Anuario del Instituto de Historia Argentina, vol. 17, nº 1, e043, junio 2017.

ISSN 2314-257X

Universidad Nacional de La Plata.

Facultad de Humanidades y Ciencias de la Educación.

Centro de Historia Argentina y Americana

\title{
Laura Caruso, Embarcados. Los trabajadores marítimos y la vida a bordo: sindicato, empresas y Estado en el puerto de Buenos Aires, 1889-1921, Buenos Aires, Imago Mundi, 2016, 320
} pp

\author{
Andrea Andújar * \\ * CONICET - Instituto Interdisciplinario de Estudios de Género - Universidad de Buenos \\ Aires, Argentina| andreaandujar@gmail.com
}

El libro de Laura Caruso nos ofrece un estudio minucioso de los trabajadores embarcados del puerto de Buenos Aires en un lapso temporal de largo aliento. Guiado por el propósito de comprender sus experiencias a partir del examen de su labor cotidiana, sus organizaciones, demandas, protestas e itinerarios políticos, su análisis se abre en 1889 con la primera huelga de los marineros que se extendió además, por diversos sectores. Concluye con otro paro, el de 1921, cuyo desenlace contuvo también una clausura, la del ciclo ascendente de la conflictividad protagonizada por los marítimos y la de su más singular conquista, el control sindical de la contratación a bordo.

Si en la elección del sujeto de esta historia, de su objetivo y de los acontecimientos que delimitan el período en consideración se vislumbra la preferencia de la autora por un enfoque asentado en la historia social, internarse en las páginas de Embarcados... revela los alcances de esa decisión a la luz, particularmente, de las apuestas y los desafíos interpretativos que asume. Entre ellos ocupa un lugar destacado el afán por conjugar categorías, nociones y claves analíticas surgidas en distintas tradiciones teóricas. Así, en la preocupación por escudriñar el mundo del trabajo marítimo en función de los sujetos que lo componen, sus relaciones, conflictos, valores, percepciones e identidad política, tema al que se aboca en el primero de los cinco capítulos en los que se organiza la obra, se distingue una pátina thompsoniana a la que se indexa el interés por una lectura desde el género. La misma se aprecia, fundamentalmente, en la disposición a indagar la masculinidad de los trabajadores de a bordo no como una condición natural o un dato descriptivo de la composición de la fuerza laboral, sino como una construcción histórica que incide en su experiencia de clase, 
en su identidad, en la articulación de sus reivindicaciones o en la arquitectura de sus organizaciones gremiales. Otra muestra de los beneficios de la mixtura de estas perspectivas puede advertirse en el estudio del proceso de trabajo de a bordo, dimensión a la que conjuntamente con el puerto y las embarcaciones -escenarios en los que ese mundo cobraba existencia-, la autora brinda particular realce analítico. La comprensión de los diversos aspectos de tal proceso así como las innovaciones de las que fue objeto sucesivamente es inscripta en el terreno de las relaciones obrero-patronales y en consecuencia, como producto de la interacción conflictiva entre los trabajadores y sus adversarios de clase, los empresarios marítimos. De tal modo, Caruso sitúa el proceso laboral y su decurso en la manera en que la clase trabajadora experimentó la explotación y pugnó en su contra -superando en las formas de organización y en las practicas de lucha su fragmentación inicial-, y en las respuestas o iniciativas articuladas por la patronal naviera frente a ello. De ella se encarga, por su parte, en el siguiente capítulo.

La incursión en los papeles procedentes de los empresarios navieros, algunos de los cuales son asimismo muy novedosos, reporta un conocimiento pormenorizado de la expansión de este sector de la burguesía local, los lazos establecidos entre sus integrantes -con sus tensiones, enfrentamientos abiertos y velados, y sus alianzas-, y su influencia política. El acento analítico recae aquí en la compañía Mihanovich, la mayor empresa naviera de la Argentina en ese entonces y la flota mercante mas importante en Sudamérica. Y no sólo eso.También fue una de las más dinámicas y firmes promotoras de un frente patronal anti-sindical, estimulando la formación de diversas asociaciones y centros en simultaneidad con el despliegue de variados mecanismos de presión sobre los funcionarios del Estado. Justamente, el libro da cuenta de estas y otras estrategias que las dirigencias navieras, concientes de su lugar cardinal para el funcionamiento de la economía, ensayaron a los fines de volcar a su favor la lucha de clases. Tales ensayos, que comprendían desde el lock out patronal y el uso de la violencia desembozada contra los trabajadores hasta la conformación de una sociedad de socorros mutuos patrocinada por la empresa Mihanovich, adquieren en este trabajo un claro sentido de tentativas. Se trata de experimentos realizados en un escenario donde ni el carácter de los desafíos planteados por los trabajadores al poder empresarial ni las respuestas de este último son examinadas a la luz de los resultados posteriores del conflicto. En todo caso, la habilidad de Caruso para interrogar las fuentes sin desatender el margen de incertidumbre en que los sujetos actuaron, pensaron y vivieron mientras hacían su propia historia, y su perseverancia en una perspectiva relacional (si bien situada siempre en el punto de mira de la clase trabajadora), postulan una comprensión del pasado de esos sujetos y sus relaciones en un relieve dinámico cuya trama no sigue un curso lineal sino sinuoso, permeado por aprendizajes y apuestas variadas, en ocasiones fallidas y a veces exitosas en su intento por ganar terreno en medio de enfrentamientos sin final anunciado.

El capítulo cuarto y el quinto se adentran por esas apuestas, mas deteniéndose en las originadas en el ámbito de la práctica sindical. En la revisión de esta arista de la experiencia obrera es posible advertir nuevamente la predilección de la autora por combinar coordenadas analíticas de procedencia variada. Caruso reconstruye con detalle los agrupamientos gremiales que fueron sucediéndose entre los trabajadores del puerto, sus adscripciones político-ideológicas, los alcances de su representatividad, de su prédica y las luchas en las que participaron, entre las que destacan las huelgas y boicots dentro de un arco nutrido y prolífico de actividades de propaganda, agitación y confrontación. Si en tales pasajes pueden reconocerse los trazos de una historiografía sindical más habitual, también es factible observar cómo la autora logra sortear una trampa recurrente en ella: la de entender la dinámica política y beligerante de los trabajadores desde una perspectiva institucional y por tanto, asociada dominantemente a las directivas, voluntades o programas de las corrientes políticas y/o sindicales vigentes. Presta especial atención para eso a las actividades y los vínculos forjados no sólo en los espacios y momentos de trabajo sino también en los ámbitos de descanso y en el tiempo libre, siguiendo en unos y otros las pistas de las vivencias, prácticas e intereses compartidos en los que habrían 
anidado las demandas y protestas colectivas. De tal modo, repone la historia del sindicalismo revolucionario y de la poderosa Federación Obrera Marítima (FOM), creada hacia 1910, desde una suerte de mirada "a ras del suelo" que, sin soslayar las trayectorias y habilidades políticas de la dirigencia obrera marítima, reconoce las iniciativas de los propios trabajadores y la incidencia de la experiencia previamente acumulada. Y más aún. Esta forma de mirar le posibilita advertir cómo esas iniciativas y esa experiencia moldearon las propuestas organizativas y políticas de la influyente corriente sindicalista. Asimismo, los pasos seguidos por la FOM durante su primera década de existencia, con su organización interna y las formas y practicas adoptadas por sus militantes son escudriñados detalladamente. Resalta en ese plano la capacidad de la Federación para volverse un lugar de encuentro en condiciones de aglutinar a los trabajadores superando las fragmentaciones devenidas de las diferencias de oficios, categorías, jerarquías o étnico-nacionales, y sobreponiéndose a la dispersión geográfica mediante la apertura de seccionales en lugares como la costa patagónica o el litoral. Sin dudas, uno de los mayores logros de esta experiencia fue el control sindical de la contratación de los trabajadores y de las condiciones de trabajo a bordo, exigencia enarbolada infructuosamente por otros sindicatos que persistieron en tal reclamo durante mucho tiempo (tal el caso, por ejemplo, de la Unión General de Obreros Petroleros, fundada al principiar la década de 1930 en Comodoro Rivadavia de la mano de militantes comunistas). La satisfacción de este anhelo estuvo asociada, por otra parte, a la alianza tejida con capitanes y oficiales, la cual se aceitó hacia fines de 1916 durante la huelga general marítima llevada a cabo prácticamente en los albores de la primera presidencia radical. Este conflicto, escasamente estudiado por la historiografía, fue sumamente trascendente tanto en el plano organizativo como en aquel relativo a la vinculación con el gobierno de Hipólito Yrigoyen.

Los lazos entre el sindicalismo marítimo y determinados representantes del poder político conforman el nudo del quinto y último capítulo de Embarcados .... En base a un exhaustivo examen de diferentes documentos, fundamentalmente los originados en el Departamento Nacional del Trabajo y los códigos, reglamentos y disposiciones que regulaban la vida y el trabajo a bordo, la autora pone en tensión interpretaciones consagradas sobre la genealogía de tales vínculos demostrando que, a diferencia de lo sostenido comúnmente, los acercamientos entre los sindicatos y el Estado precedieron largamente a la primera presidencia radical. El examen los orígenes, razones y contenidos de estas relaciones encuentra nuevamente a Embarcados ... buceando "desde abajo", preocupado por responder a estas preguntas a la luz de las expectativas de la clase trabajadora y sus organizaciones gremiales. Esto no significa desatender las acciones del Estado hacia los trabajadores de a bordo. Así, repasa las políticas emprendidas por los gobiernos conservadores denotando prácticas que oscilaban entre represión y arbitraje, entre el ejercicio de violencia y la creación de organismos específicamente vinculados al mundo laboral o el reconocimiento de algunos derechos laborales a partir del impulso de ciertas leyes, por ejemplo. Sin embargo, el interés medular está colocado en la manera y los motivos por los que la clase trabajadora alentó el acercamiento con los poderes públicos, los ritmos que siguió tal acercamiento y su decurso durante la primera presidencia radical.

En suma, en las páginas de este libro, Laura Caruso nos brinda una historia de los trabajadores de a bordo del puerto de Buenos Aires audaz en sus opciones teóricas, exhaustiva en la variedad de fuentes consultadas, provocadora en las hipótesis y en los argumentos que pone en juego, dispuesta a confrontar abiertamente con algunas interpretaciones largamente instaladas pero también, a reconocer sus aportes y a nutrirse de ellos. Inscripto en una saga de estudios que vienen renovando el campo de la historia social del trabajo, Embarcados ... es, sin dudas, una de sus más alentadoras y potentes expresiones. 